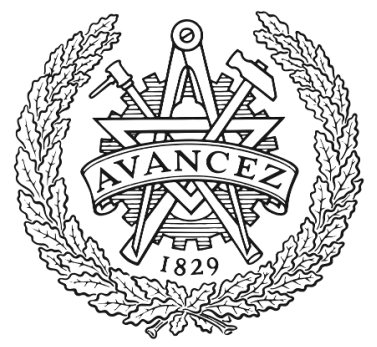

CHALMERS

UNIVERSITY OF TECHNOLOGY

\title{
The Association of Red Meat Intake with Inflammation and Circulating Intermediate Biomarkers of Type 2 Diabetes Is Mediated by Central
}

Downloaded from: https://research.chalmers.se, 2023-04-26 00:11 UTC

Citation for the original published paper (version of record):

Mazidi, M., Kengne, A., George, E. et al (2021). The Association of Red Meat Intake with Inflammation and Circulating Intermediate Biomarkers of

Type 2 Diabetes Is Mediated by Central Adiposity. British Journal of Nutrition, 125(9): 1043-1050. http://dx.doi.org/10.1017/S0007114519002149

N.B. When citing this work, cite the original published paper. 
The Association of Red Meat Intake with Inflammation and Circulating Intermediate Biomarkers of Type 2 Diabetes Is Mediated by Central Adiposity

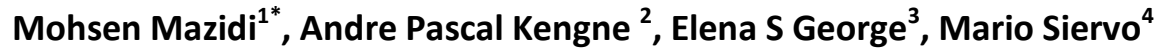

1-Department of Biology and Biological Engineering, Food and Nutrition Science, Chalmers University of Technology, SE-412 96 Gothenburg, Sweden.

2-Non-Communicable Disease Research Unit, South African Medical Research Council and University of Cape Town, Cape Town, South Africa, Andre.Kengne@mrc.ac.za

3-Institute for Physical Activity and Nutrition, School of Exercise and Nutrition Sciences, Deakin University, Geelong, Australia

4- School of Life Sciences, The University of Nottingham Medical School, Queen's Medical Centre, Nottingham, NG7 $2 U H, U K$

Running title: Red Meat Consumption and Cardio-Metabolic Risk

*Corresponding Author: Mohsen Mazidi. Department of Biology and Biological Engineering, Food and Nutrition Science, Chalmers University of Technology, SE-412 96 Gothenburg, Sweden. E-mail: mazidi@chalmers.se

The material presented in this manuscript is original and it has not been submitted for publication elsewhere.

Conflict of interest statement: The authors have no conflict of interest to declare.

Type of Manuscript: Original Research

Abstract word count: 233

This peer-reviewed article has been accepted for publication but not yet copyedited or typeset, and so may be subject to change during the production process. The article is considered published and may be cited using its DOI

$10.1017 / \mathrm{S} 0007114519002149$

The British Journal of Nutrition is published by Cambridge University Press on behalf of The Nutrition Society 


\title{
Main text word count:
}

\section{References:}

Table: 4

Figures: 0

\begin{abstract}
We explored the role of lipid accumulation products and visceral adiposity on the association between red meat consumption and markers of insulin resistance (IR) and inflammation in US adults. Data on red meat consumption, and health outcome measurements were extracted from the 2005-2010 US National Health and Nutrition Examination Surveys. Overall 16,621 participants were included in the analysis (mean age $=47.1$ years, $48.3 \%$ men). Analysis of covariance and "conceptus causal mediation" models were applied, while accounting for survey design. In adjusted models, a lower red meat consumption was significantly associated with a cardioprotective profile of IR and inflammation. Body mass index (BMI) had significant mediation effects on the associations between red meat consumption and C-reactive protein (CRP), Apolipoprotein-B, fasting glucose (FBG), insulin, homeostatic model assessment (HOMA) IR and $\beta$-cell function, glycated haemoglobin (HbA1c), triglyceride to high density lipoprotein (TG:HDL) ratio and triglyceride-glucose (TyG) index (all $p<0.05$ ). Both waist circumference and anthropometrically predicted visceral adipose tissue (apVAT) mediated the association between red meat consumption with CRP, FBG, HbA1c, TG: HDL ratio and TyG index (all $p<0.05$ ). Our findings suggest that adiposity, particularly the accumulation of abdominal fat, accounts for a significant proportion of the associations between red meat consumption IR and inflammation.
\end{abstract}

Keywords: Meat Intake, Inflammation, Glucose Haemostasis, Insulin Resistance, Adiposity.

\section{Introduction}

Red meat consumption has been associated with a pro-inflammatory status, which in turn has been related to a higher risk for type 2 diabetes (1), metabolic syndrome (2) and coronary heart disease (2). The Multi-Ethnic Cohort Study and Nurses' Health Study reported that a high red meat consumption was linked to approximately $40 \%$ greater risk of type 2 diabetes over a follow-up time of 14 and 4 years, respectively $(3,4)$. However, findings are not consistent across studies as a nonsignificant association was also found between risk of type 2 diabetes and red meat intake, especially for unprocessed red meat and diabetes risk $(5,6)$. 
Despite the conflicting literature surrounding red meat consumption and risk of type 2 diabetes, there is evidence to suggest that increased red meat consumption is associated with increased whole-body and central adiposity (7). These findings may contribute to explaining the significant association between red meat consumption and type 2 diabetes as central adiposity is a more sensitive predictor of type 2 diabetes and other obesity-related chronic diseases compared to BMI (8).

The role of visceral fat as a causal factor connecting obesity and weight gain to the pathogenesis of insulin resistance and atherosclerosis is established (9). Waist circumference has been proposed as a rapid and simple measurement for the assessment of abdominal adiposity but, like body mass index (BMI), is not able to discriminate between subcutaneous and visceral abdominal fat depots (10). Hence, additional simple and integrated indexes have been recently proposed by combining physical (i.e., waist circumference, BMI, thigh circumference, age) and biochemical measures [(i.e., triglycerides, blood glucose or high density lipoproteins (HDL)]. The lipid accumulation product (LAP) index is a marker of central fat accumulation, derived from the measurements of waist circumference and circulating triglycerides (11), which has been proposed as a predictor of insulin resistance (IR), metabolic syndrome (MetS), type 2 diabetes mellitus and cardiovascular diseases $(12,13)$. The visceral adiposity index (VAI) is another indicator of adipose tissue distribution which has been used in the stratification of adult obesity phenotypes (14) and to improve the prediction of cardio-metabolic risk (15).

Regression analysis is frequently used to evaluate the association between dietary factors and disease risk but it may be characterised by a limited capacity to identify putative biological mechanisms which could possibly explain the association between red meat intake and risk of high inflammation and impaired glucose control (16). Mediation analysis is a more sensitive statistical approach that can be used to explore and quantify the extent to which the relationship between an exposure and an outcome of interest occurs through the effect of a third variable $(16,17)$. The traditional approach to mediation analysis tends to produce a bias when the interaction between exposure and mediator is undefined $(18,19)$. In addition, unbiased valid estimates of direct and indirect effects can be obtained with the use of the counterfactual framework in causal mediation analysis $(18,19)$. It is unclear to what extent the adjustment for adiposity, modifies or attenuates the association between meat consumption and cardio-protective parameters. Mediation analysis could clarify the role of adiposity underlying the relation between meat consumption and cardioprotective factors. 
Previous studies have investigated the association between red meat intake with biomarkers of inflammation and glucose/insulin metabolism with mixed results (20-23); however, none of these studies has attempted to identify which intermediate factors connect the exposure to red meat with the selected health outcomes. The present analysis aims to specifically investigate the link between red meat intake with CRP and glucose/insulin haemostasis and identify adiposity factors that may mediate these associations. These factors include markers of adiposity [WC, BMI, visceral adipose tissue (VAT)], lipid accumulation products (LAP) and visceral adiposity index (VAI) in a representative population of US adults by using National Health and Nutrition Examination Survey (NHANES) database. We hypothesized that a higher red meat intake would be associated with unfavourable concentrations of inflammatory and glucose/insulin haemostasis biomarkers among adults and that these associations would be partly or fully mediated by adiposity markers.

\section{Methods}

\section{Population characteristics}

The NHANES programme is implemented by the US National Center for Health Statistics (NCHS) (24). NHANES uses a complex, multistage and stratified sampling design to select a representative sample of the civilian and non-institutionalized resident population of the US. The NCHS Research Ethics Review Board approved the NHANES protocol and consent was obtained from all participants (24). The current study was based on analysis of data collected from 2005 to 2010. Data collection on demographics occurs through in-home administered questionnaires, while anthropometric and biochemistry data are collected by trained personnel using mobile exam centers (MEC). More detailed information is available elsewhere $(24,25)$.

For the assessment of height and weight during the physical examination, participants were dressed in underwear, disposable paper gowns and foam slippers. A digital scale ('Mettler Toledo, Panther') was used to measure weight to the nearest $100 \mathrm{~g}$, a fixed stadiometer was used to measure height to the nearest millimetre. Body mass index (BMI) was calculated as weight in kilograms divided by the square of height in metres. Waist circumference (WC) was measured at the iliac crest to the nearest millimetre (25).

A blood specimen was drawn from the participant's antecubital vein by a trained phlebotomist. Glycated haemoglobin (HbA1c) was measured using a Tosoh A1C 2.2 Plus Glycohemoglobin Analyzer. Fasting blood glucose (FBG) was measured by a hexokinase method using a Roche/Hitachi 911 Analyzer and Roche Modular P Chemistry Analyzer. Insulin was measured using an ELISA immunoassay (Merocodia, Uppsala, Sweden) (26). Other laboratory-test details are available in the NHANES Laboratory/ Medical Technologists Procedures Manual (27). Apolipoprotein-B was 
measured by radial immunodiffusion (RID) (25). Details on the measurement of C-reactive protein (CRP) concentrations are available elsewhere (25). Homeostatic model assessment of insulin resistance (HOMA-IR), $\beta$-cell function (HOMA-B) and insulin sensitivity (HOMA-IS) were calculated as follows: $\mathrm{HOMA}-\mathrm{IR}=[\mathrm{FBG}(\mathrm{nmol} / \mathrm{L}) *$ insulin $(\mathrm{mU} / \mathrm{mL}) / 22.5]$, and HOMA-B $=[20 \times$ insulin $(\mu \mathrm{U} / \mathrm{ml})] /$ [FBG (mmol/l) - 3.5] (28). The triglyceride-glucose (TyG) index was calculated as the In[triglyceride $(T G, m g / d l) \times F B G(m g / d l) / 2](29)$. Visceral adipose tissue (apVAT) was predicted with sex-specific validated equations that included age, BMI, and circumferences of the waist and thigh (30). The equation for men was: 6 *WC $-4.41 *$ proximal thigh circumference $+1.19 *$ age -213.65 ; and the equation for women was: $2.15 * \mathrm{WC}-3.63 *$ proximal thigh $+1.46 *$ age $+6: 22 * \mathrm{BMI}-92.713$ (30). VAI was calculated using sex-specific formulas: males $[\mathrm{WC} / 39.68+(1.88 \times \mathrm{BMI})] \times(\mathrm{TGs} / 1.03) \times$ (1.31/high density lipoprotein (HDL)); females: [WC/36.58 + (1.89 × BMI)] $\times(T G s / 0.81) \times(1.52 / H D L)$, where both TGs and HDL levels are expressed in mmol/L (15). LAP was calculated as [WC-65] $\times$ [TG] in men, and [WC-58] $\times[T G]$ in women (11). Smoking status was self-reported and participants classified as current smoker or not. Metabolic equivalent of task (MET) is used to measure the intensity level of physical activity and indicated the rate of energy consumption for a specific activity. A MET is defined as $1 \mathrm{kcal} / \mathrm{kg} /$ hour that is roughly equal to the energy cost of being at rest. Physical activity was categorized into three intensity levels upon MET score: light, moderate and vigorous (31). Subjects with diabetes were excluded from the study.

\section{Red meat consumption}

Dietary intake was assessed via a 24-hour recall obtained by a trained interviewer during the MEC visit, with the use of a computer-assisted dietary interview system with standardized probes, i.e. the United States Department of Agriculture Automated Multiple-Pass Method (AMPM) $(32,33)$. Briefly, the type and quantity of all foods and beverages consumed in a single 24-hour period before the dietary interview (from midnight to midnight) were collected with the use of the AMPM. AMPM is designed to enhance complete and accurate data collection while reducing respondent burden $(33,34)$. Detailed descriptions of the dietary interview methods are provided in the NHANES Dietary Interviewer's Training Manual (35). The MyPyramid Equivalents Database for USDA Survey Food Codes was used to calculate red meat consumption (35). In the current study red meat intake was calculated as the sum of beef, pork, lamb, veal and game consumption and expressed as grams per day. 


\section{Statistical analysis}

Analyses were conducted using the SPSS software (version 22, Chicago, IL, USA) according to the guidelines set forth by the center for disease and prevention (CDC) for analysis of complex NHANES datasets, accounting for the masked variance and using the proposed weighting methodology (36). We used means and standard error mean for continuous measures (analysis of variance) and percentages for categorical variables (Chi-square). Analysis of covariance (ANCOVA) was used to compute age, race, energy intake, and sex-adjusted means of markers of insulin resistance or inflammation across quartiles of meat consumption.

The counterfactual framework assessed the total, direct, and indirect effects of red meat consumption on markers of insulin resistance or inflammation with BMI, WC, apVAT, VAI and LAP as a mediator $(37,38)$. In this approach, the "total effect" can be decomposed into a "direct effect" (not mediated by BMI, WC, apVAT, VAI and LAP, sup Fig1) and an "indirect effect" (mediated by BMI, WC, apVAT, VAI and LAP, sup Fig1). The analysis was conducted using the SPSS Macro developed by Preacher and Hayes (39). A product-of-coefficients test was used as it has the potential to detect significant mediation effects in the absence of a significant intervention effect $(37,38)$. In brief, the macro generates outputs that include the following steps. Firstly, the "total effect" ( $\gamma$ coefficient) of the exposure on the outcome variable (i.e., markers of insulin resistance or inflammation) is estimated by regressing the markers of insulin resistance or inflammation (outcomes) on red meat consumption (independent variable) while adjusting for the covariates used in the first step, but without adjusting for mediators. The "action theory" test is then used to examine the effect of the exposure (meat consumption) on the hypothesized mediators ( $\alpha$ coefficient, BMI, WC, apVAT, VAI and LAP, sup Fig1). The "conceptual theory" test examines the association between changes in the hypothesized mediators and changes in outcome variables (i.e., markers of insulin resistance or inflammation; $\beta$ coefficient, sup Fig 1). The program also estimates the direct ( $\gamma^{\prime}$ coefficient) and indirect ( $\alpha \# \beta$ product of coefficients) effects. The proportion of the mediation effect was calculated using the following equation $[\alpha \# \beta /(\alpha \# \beta+\gamma)]$. Full or complete mediation is present when the total effect (the $\gamma^{\prime}$-path) is significant, the direct effect (the $\gamma^{\prime}$-path) is not significant and $\alpha \# \beta$ is significant, whereas partly or incomplete mediation is present when the direct effect (the $\gamma^{\prime}$-path) is also significant. Inconsistent mediation is present when neither total nor direct effect is significant and $\alpha \# \beta$ is significant(40). All estimates were adjusted for age, sex, race/ethnicity, educational, smoking and level of physical activity. 


\section{Results}

\section{General characteristics}

A total of 16,621 subjects met the criteria for inclusion in the current analyses. Overall 8,607 (48.3\%) participants were men and the mean age was 47.1 years. Non-Hispanic white (69.4\%) was the largest racial group and other Hispanic (4.5\%) the smallest racial group. Furthermore, $56.1 \%$ of the participants were married, while $56.4 \%$ had achieved more than high school education. Mean and standard error for BMI, WC, apVAT were $28.7 \pm 0.05 \mathrm{~kg} / \mathrm{m}^{2}, 98.2 \pm 0.12 \mathrm{~cm}$ and 179.2 \pm 1.18 , respectively. Overall, $20.1 \%$ were current smokers including $24.7 \%$ of men and $15.7 \%$ of women. Participants engaging in vigorous physical activity represented $5.2 \%$ of the participants, and those engaging in little/no physical activity represented 24.3\%. Age, sex, and race-adjusted mean of markers of insulin resistance and inflammation (hs-CRP, apolipoprotein B, FBG, insulin, HOMA-IR, HOMA-B and TyG index) significantly increased across quartiles of red meat consumption (all p<0.001, Table 1); HbA1c was not associated with red meat consumption (Table 1).

\section{Red meat intake, anthropometry, insulin resistance and inflammation}

Action theory: After covariates adjustment, there was a significant association between red meat intake and BMI $(\beta: 0.345, p<0.001)$, WC $(\beta: 0.912, p<0.001)$, apVAT $(\beta: 3.27, p<0.001)$, VAI $(\beta: 0.054$, $p<0.001)$ and LAP $(\beta: 0.066, p<0.001)$ (Table 2).

Total effect: This was calculated by examining the association between red meat intake and markers of insulin resistance or inflammation in multivariate models without adjusting for potential mediators. Results showed that, with the exception of HbA1c and HOMA-B, all the markers of insulin resistance or inflammation were positively and significantly associated with red meat intake (all $\mathrm{p}<0.04$, Table 2).

Conceptual theory: This analysis tested the association between mediators (BMI, WC, apVAT, VAI and LAP) and markers of insulin resistance or inflammation; all potential mediators had significant and positive associations with markers of insulin resistance or inflammation (all $p<0.001$, Table 3).

\section{Direct and indirect effects of red meat consumption on insulin resistance and inflammation}

Table 4 shows the "direct effect", "indirect effect", proportion of mediation effect, and Sobel statistics for testing indirect effects. Both BMI and WC significantly mediated the association between markers of insulin resistance and inflammation and red meat intake (all $\mathrm{p}<0.001)$; BMI and WC showed the greatest effect on FBG $(\beta=0.312, \beta=0.371$, respectively). apVAT was a significant mediator for the association between red meat intake with CRP, FBG, HbA1c and TyG index (all $p<0.001)$; similarly FBG was the variable with the strongest association with apVAT $(\beta=0.293)$. Both 
VAI and LAP mediated the association between red meat intake and markers of insulin resistance and inflammation (all $\mathrm{p}<0.001$ ); Serum Apolipoprotein (B) was the variable with the strongest association with VAl and LAP $(\beta=0.682, \beta=0.808$, respectively).

\section{Discussion:}

In the current study we demonstrated that red meat intake was significantly associated with all anthropometric outcomes (BMI, WC, apVAT, VAI and LAP) in fully adjusted models. Red meat intake was also significantly associated with markers of insulin resistance, (except for HbA1c and HOMA-B), and with inflammation. In addition, mediation analyses suggested that these significant associations were partly or fully mediated by central adiposity.

A systematic review reported a significant link between red meat intake, especially processed varieties, with risk of breast cancer (41). Existing observational and intervention studies testing the association between red meat consumption wand CRP levels have reported mixed results. Findings were significant in some studies $(20,22)(42)$ which is in line with what was found in this study. However other studies have findings contradictory to what our study showed demonstrating that while processed meat was positively associated with CRP, red meat consumption alone was not (23) and in another study where lean red meat was not associated with levels of CRP (43). The cholesterol $(44)$, iron $(45)$ and saturated fatty acid $(44,46)$ content of red meat has been suggested, to some extent, to explain the association between red meat and adverse health outcomes. $(47,48)$.Previous studies on the effect of meat consumption on glucose/insulin homeostasis have been inconsistent, with some finding an association, in line with our study (49-52), and other failing to show such an association $(21,22)$. It has been reported that red meat consumption may have impact on glucose/insulin metabolism though iron-related metabolic pathways (53). Iron is a strong pro-oxidant that catalyses several cellular reactions involved in the production of reactive oxygen species, and hence increases the level of oxidative stress (54). This can cause damage to cellular structures, including pancreatic beta cells, and high body iron stores have been shown to be associated with an elevated risk of diabetes (54). Once iron accumulated in the liver, it could interrupt with role of insulin and also constrain the glucose production (55). Increased iron accumulation might lead to insulin resistance by constraining glucose uptake in different tissues (53). Clinical studies have shown no significant effect of iron supplementation on CRP levels (45).

Additionally, the effect of red meat on uric acid levels could constitute another pathway linking this dietary component with glucose/insulin homeostasis dysregulation (56). It has been reported that uric acid could play a role in oxidative stress (57) and inflammatory factors (57), which are both linked to the progress of unfavourable glucose/Insulin homeostasis $(56,57)$. Further, an experiment 
in animal models reported that fructose-induced hyperuricemia plays a pathogenic role in developments of cardio-metabolic risk factors (58).

A prolonged intake of saturated fatty acids is correlated metabolic syndrome and is known to contribute to weight gain and inflammation if consumed in excess $(59,60)$. In particular saturated fatty acids are known to contribute to increases in influence white adipose tissue increasing inflammatory response (61-63). Hence, we hypothesised that a high energy diet which contains excess red meat consumption and is high in saturated fatty acids may be associated with weight gain and thus increased adiposity and subsequently contribute to developing unfavourable glucose/insulin homeostasis enhancing low grade inflammation which is strongly linked to the pathogenesis of CVD and other non-communicable disease. The role of dietary factors, such as excess refined sugar or saturated fat intake, on triggering low grade chronic inflammatory response has received further scientific support recently, reiterating the link with age- related chronic conditions. These inflammatory responses are thought to interact with the ageing process and, if persisted could play a key role in the pathogenic mechanisms leading to the onset of chronic metabolic and cardiovascular diseases (64).

The main strength of the present study is the investigation of the mediation effects using various markers of adiposity including not only $\mathrm{BMI}$ and $\mathrm{WC}$, which are the markers of general and abdominal obesity, but also apVAT, VAI and LAP. Moreover we have used a randomly selected, large and representative sample and our results can be extrapolated to the general population. Lastly, the analyses included extensive adjustment for potential confounders which reduces the chance of the residual confounders.

The study has limitations. The study is cross sectional and focused on adults only. Cohort studies may better address the causal relation between red meat intake and relevant health outcomes, but may not be feasible because of the nature of the exposure and ethical issues. Consumption reported associations do not necessarily mean causation. Consumption of red meat in different life stages (childhood, adolescents adulthood and during ageing) has been previously shown to affect risk estimates (65). Furthermore, different patterns of exposure over time could also affect the results. Cooking methods and variations in animal farming and meat preparation, can alter the quality as well as the health effects of red meats $(66,67)$. This introducing additional residual confounding into the analyses (68-70). This information was not available and therefore could not be controlled. The mediating effect of WC may be affected by BMI, or vice versa, because of the high colinearity between these two variables. This issue could be resolved by adding BMI and WC simultaneously to the mediation model (45). However, this approach was not possible in our analyses because of the complex survey design of the present study. Hence, in an attempt to overcome this limitation, we 
have added other validated adiposity factors to the models such as apVAT, LAP and VAI, which provides an independent evaluation of the mediating role of central adiposity between red meat intake and markers of diabetes risk. Lastly, although BMI and WC are regularly applied to determine adiposity, these indicators are still imprecise and can lead to bias in determining obesity. For instance, $\mathrm{BMI}$, is usually limited compared to direct measures of obesity due to the fact that it does not consider age, sex, bone structure, fat distribution or muscle mass into (71). However, we also used other markers of adiposity (apVAT and LAP) which are sensitive to the age, and sex.

\title{
Conclusion:
}

Our study finding suggests that high red meat consumption could negatively affect glucose/insulin homeostasis and inflammatory profile, via mechanisms involving central fat accumulation. Future research is warranted to explore the effect of reducing red meat intake on glucose/insulin homeostasis, which in turn could inform dietary strategies to reduce the risk of T2DM.

Availability of data and material: all the data are from public access database.

\author{
Abbreviations: \\ Red meat consumption (RMC) \\ insulin resistance (IR) \\ Homeostatic model assessment (HOMA) \\ C-reactive protein (CRP) \\ Body mass index (BMI) \\ anthropometrically predicted visceral adipose tissue (apVAT) \\ triglyceride-glucose (TyG) \\ fasting glucose (FBG) \\ high density lipoprotein (TG:HDL) \\ glycated haemoglobin (HbA1c) \\ lipid accumulation product (LAP) \\ metabolic syndrome (MetS) \\ high density lipoproteins (HDL)
}


visceral adiposity index (VAI)

National Center for Health Statistics (NCHS)

mobile exam centers (MEC)

National Health and Nutrition Examination Survey (NHANES)

Metabolic equivalent of task (MET)

Agriculture Automated Multiple-Pass Method (AMPM)

center for disease and prevention (CDC)

Analysis of covariance (ANCOVA)

\section{Competing financial interests:}

The corresponding author is responsible for submitting a competing financial interest statement on behalf of all authors of the paper. The authors declare no competing financial interests.

Funding: None

Acknowledgments: None

Author Contributions:

MM: Study conception and design, Analysis and interpretation of data. Drafting of manuscript.

APK, ESG and MS: Critical revision and interpretation of data.

\section{Declarations:}

Ethics approval and consent to participate: for the data collection and physical examination of the NHANES, informed consent was obtained from all adult participants, and the National Centre for Health Statistics Research Ethics Review Board approved the protocol

Consent for publication: for the data collection and physical examination of the NHANES, informed consent (publication) was obtained from all adult participants, and the National Centre for Health Statistics Research Ethics Review Board approved the protocol.

Availability of data and material: all the data are from public access database.

\section{References}

1. van Woudenbergh GJ, Kuijsten A, Tigcheler B, Sijbrands EJ, van Rooij FJ, Hofman A, et al. Meat consumption and its association with C-reactive protein and incident type 2 diabetes: the Rotterdam Study. Diabetes care. 2012;35(7):1499-505.

2. Azadbakht L, Esmaillzadeh A. Red meat intake is associated with metabolic syndrome and the plasma C-reactive protein concentration in women. The Journal of nutrition. 2009;139(2):335-9. 3. Steinbrecher A, Erber E, Grandinetti A, Kolonel LN, Maskarinec G. Meat consumption and risk of type 2 diabetes: the Multiethnic Cohort. Public health nutrition. 2011;14(4):568-74.

4. Pan A, Sun Q, Bernstein AM, Manson JE, Willett WC, Hu FB. Changes in red meat consumption and subsequent risk of type 2 diabetes mellitus: Three cohorts of us men and women. JAMA Internal Medicine. 2013;173(14):1328-35. 
5. Pan A, Sun Q, Bernstein AM, Schulze MB, Manson JE, Willett WC, et al. Red meat consumption and risk of type 2 diabetes: 3 cohorts of US adults and an updated meta-analysis. The American journal of clinical nutrition. 2011;94(4):1088-96.

6. Ley SH, Sun Q, Willett WC, Eliassen AH, Wu K, Pan A, et al. Associations between red meat intake and biomarkers of inflammation and glucose metabolism in women. The American journal of clinical nutrition. 2014;99(2):352-60.

7. Wang Y, Beydoun MA. Meat consumption is associated with obesity and central obesity among US adults. International journal of obesity (2005). 2009;33(6):621-8.

8. Wang Y, Rimm EB, Stampfer MJ, Willett WC, Hu FB. Comparison of abdominal adiposity and overall obesity in predicting risk of type 2 diabetes among men. The American journal of clinical nutrition. 2005;81(3):555-63.

9. Grundy SM. Obesity, metabolic syndrome, and coronary atherosclerosis. Circulation. 2002;105(23):2696-8.

10. Romero-Corral A, Somers VK, Sierra-Johnson J, Thomas RJ, Collazo-Clavell ML, Korinek J, et al. Accuracy of body mass index in diagnosing obesity in the adult general population. Int J Obes (Lond). 2008;32(6):959-66.

11. Onat A, Avci GS, Barlan MM, Uyarel H, Uzunlar B, Sansoy V. Measures of abdominal obesity assessed for visceral adiposity and relation to coronary risk. Int J Obes Relat Metab Disord. 2004;28(8):1018-25.

12. Mirmiran P, Bahadoran Z, Azizi F. Lipid accumulation product is associated with insulin resistance, lipid peroxidation, and systemic inflammation in type 2 diabetic patients. Endocrinology and Metabolism. 2014;29(4):443-9.

13. Wakabayashi I, Daimon T. A strong association between lipid accumulation product and diabetes mellitus in japanese women and men. Journal of atherosclerosis and thrombosis. $2014 ; 21(3): 282-8$.

14. Du T, Yu X, Zhang J, Sun X. Lipid accumulation product and visceral adiposity index are effective markers for identifying the metabolically obese normal-weight phenotype. Acta diabetologica. 2015;52(5):855-63.

15. Amato MC, Giordano C, Galia M, Criscimanna A, Vitabile S, Midiri M, et al. Visceral Adiposity Index: a reliable indicator of visceral fat function associated with cardiometabolic risk. Diabetes Care. 2010;33(4):920-2.

16. Fairchild AJ, McDaniel HL. Best (but oft-forgotten) practices: mediation analysis. Am J Clin Nutr. 2017.

17. Baron RM, Kenny DA. The moderator-mediator variable distinction in social psychological research: conceptual, strategic, and statistical considerations. Journal of personality and social psychology. 1986;51(6):1173-82.

18. Richiardi L, Bellocco R, Zugna D. Mediation analysis in epidemiology: methods, interpretation and bias. Int J Epidemiol. 2013;42(5):1511-9.

19. Robins JM, Greenland S. Identifiability and exchangeability for direct and indirect effects. Epidemiology. 1992;3(2):143-55.

20. Azadbakht L, Esmaillzadeh A. Red meat intake is associated with metabolic syndrome and the plasma C-reactive protein concentration in women. The Journal of nutrition. 2009;139(2):335-9.

21. Babio N, Sorlí M, Bulló M, Basora J, Ibarrola-Jurado N, Fernández-Ballart J, et al. Association between red meat consumption and metabolic syndrome in a Mediterranean population at high cardiovascular risk: cross-sectional and 1-year follow-up assessment. Nutrition, Metabolism and Cardiovascular Diseases. 2012;22(3):200-7.

22. Montonen J, Boeing H, Fritsche A, Schleicher E, Joost H-G, Schulze MB, et al. Consumption of red meat and whole-grain bread in relation to biomarkers of obesity, inflammation, glucose metabolism and oxidative stress. European journal of nutrition. 2013;52(1):337-45. 
23. Van Woudenbergh GJ, Kuijsten A, Tigcheler B, Sijbrands EJ, Van Rooij FJ, Hofman A, et al. Meat Consumption and Its Association With C-Reactive Protein and Incident Type 2 Diabetes. Diabetes care. 2012;35(7):1499-505.

24. Kalk WJ, Joffe BI. The metabolic syndrome, insulin resistance, and its surrogates in African and white subjects with type 2 diabetes in South Africa. Metab Syndr Relat Disord. 2008;6(4):247-55. 25. http://www.cdc.gov/NCHS/data/nhanes/nhanes 09 10/CRP F met.pdf. [accessed 19.08.13].

26. Mohsen Mazidi EDM, Maciej Banach. The association of telomere length and serum 25hydroxyvitamin D levels in US adults: the National Health and Nutrition Examination Survey. Arch Med Sci. 2017;13(1):61-5.

27. National Center for Health Statistics CfDCaPNHaNESA, http://www.cdc.gov/nchs/nhanes.htm f.

28. Musso G, Gambino R, Bo S, Uberti B, Biroli G, Pagano G, et al. Should nonalcoholic fatty liver disease be included in the definition of metabolic syndrome? A cross-sectional comparison with Adult Treatment Panel III criteria in nonobese nondiabetic subjects. Diabetes Care. 2008;31(3):562-8. 29. Simental-Mendia LE, Rodriguez-Moran M, Guerrero-Romero F. The product of fasting glucose and triglycerides as surrogate for identifying insulin resistance in apparently healthy subjects. Metabolic syndrome and related disorders. 2008;6(4):299-304.

30. Samouda H, Dutour A, Chaumoitre K, Panuel M, Dutour O, Dadoun F. VAT=TAAT-SAAT: innovative anthropometric model to predict visceral adipose tissue without resort to CT-Scan or DXA. Obesity (Silver Spring). 2013;21(1):E41-50.

31. Liu Y. The relationship between lifestyle and self-reported oral health among American adults. International dental journal. 2014;64(1):46-51.

32. Ahluwalia N, Andreeva VA, Kesse-Guyot E, Hercberg S. Dietary patterns, inflammation and the metabolic syndrome. Diabetes Metab. 2013;39(2):99-110.

33. Ahluwalia N, Dwyer J, Terry A, Moshfegh A, Johnson C. Update on NHANES Dietary Data: Focus on Collection, Release, Analytical Considerations, and Uses to Inform Public Policy. Adv Nutr. 2016;7(1):121-34.

34. Moshfegh AJ, Rhodes DG, Baer DJ, Murayi T, Clemens JC, Rumpler WV, et al. The US Department of Agriculture Automated Multiple-Pass Method reduces bias in the collection of energy intakes. Am J Clin Nutr. 2008;88(2):324-32.

35. Bowman SAF, J.E.; Moshfegh, A. . MyPyramid Equivalents Database, 2.0 for USDA Survey Foods; Food Surveys Research Group, Beltsville Human Nutrition Research Center, Agricultural Research Service, U.S. Department of Agriculture: Beltsville, MD, USA.Available online: http://www.ars.usda.gov/ba/bhnrc/fsrg (accessed on 10 April 2017). ; 2008.

36. Statistics. NCFH. ANALYTIC AND REPORTING GUIDELINES http://www.cdc.gov/nchs/data/nhanes/ nhanes 03 04/nhanes analytic guidelines dec 2005.pdf. . 37. VanderWeele TJ. Mediation and mechanism. Eur J Epidemiol. 2009;24(5):217-24.

38. VanderWeele TJ. A three-way decomposition of a total effect into direct, indirect, and interactive effects. Epidemiology. 2013;24(2):224-32.

39. Preacher KJ, Hayes AF. Asymptotic and resampling strategies for assessing and comparing indirect effects in multiple mediator models. Behavior research methods. 2008;40(3):879-91.

40. Mackinnon DP, Fairchild AJ, Fritz MS. Mediation analysis. Annual review of psychology. 2007;58:593-614.

41. Farvid MS, Stern MC, Norat T, Sasazuki S, Vineis P, Weijenberg MP, et al. Consumption of red and processed meat and breast cancer incidence: A systematic review and meta-analysis of prospective studies. International journal of cancer. 2018;143(11):2787-99.

42. Ley SH, Sun Q, Willett WC, Eliassen AH, Wu K, Pan A, et al. Associations between red meat intake and biomarkers of inflammation and glucose metabolism in women. The American journal of clinical nutrition. 2014:ajen. 075663. 
43. Hodgson JM, Ward NC, Burke V, Beilin L, Puddey IB. Increased lean red meat intake does not elevate markers of oxidative stress and inflammation in humans. The Journal of nutrition. 2007;137(2):363-7.

44. Damião R, Castro TG, Cardoso MA, Gimeno SG, Ferreira SR. Dietary intakes associated with metabolic syndrome in a cohort of Japanese ancestry. British journal of nutrition. 2006;96(03):532-8. 45. Wagener FA, Volk H-D, Willis D, Abraham NG, Soares MP, Adema GJ, et al. Different faces of the heme-heme oxygenase system in inflammation. Pharmacological reviews. 2003;55(3):551-71. 46. Esmaillzadeh A, Kimiagar M, Mehrabi Y, Azadbakht L, Hu FB, Willett WC. Dietary patterns and markers of systemic inflammation among Iranian women. The Journal of nutrition. 2007;137(4):992-8.

47. Krafft A, Perewusnyk G, Hänseler E, Quack K, Huch R, Breymann C. Effect of postpartum iron supplementation on red cell and iron parameters in non-anaemic iron-deficient women: a randomised placebo-controlled study. BJOG: An International Journal of Obstetrics \& Gynaecology. 2005;112(4):445-50.

48. Schümann K, Kroll S, Weiss G, Frank J, Biesalski H, Daniel H, et al. Monitoring of hematological, inflammatory and oxidative reactions to acute oral iron exposure in human volunteers: preliminary screening for selection of potentially-responsive biomarkers. Toxicology. 2005;212(1):10-23.

49. Feskens EJ, Sluik D, van Woudenbergh GJ. Meat consumption, diabetes, and its complications. Current diabetes reports. 2013;13(2):298-306.

50. Pan A, Sun Q, Bernstein AM, Schulze MB, Manson JE, Willett WC, et al. Red meat consumption and risk of type 2 diabetes: 3 cohorts of US adults and an updated meta-analysis. The American journal of clinical nutrition. 2011;94(4):1088-96.

51. Schulze M, Manson J, Willett W, Hu F. Processed meat intake and incidence of type 2 diabetes in younger and middle-aged women. Diabetologia. 2003;46(11):1465-73.

52. van Dam RM, Rimm EB, Willett WC, Stampfer MJ, Hu FB. Dietary patterns and risk for type 2 diabetes mellitus in U.S. men. Ann Intern Med. 2002;136(3):201-9.

53. Fernández-Real JM, López-Bermejo A, Ricart W. Cross-talk between iron metabolism and diabetes. Diabetes. 2002;51(8):2348-54.

54. Rajpathak SN, Crandall JP, Wylie-Rosett J, Kabat GC, Rohan TE, Hu FB. The role of iron in type 2 diabetes in humans. Biochimica et Biophysica Acta (BBA)-General Subjects. 2009;1790(7):671-81.

55. Niederau C, Berger M, Stremmel W, Starke A, Strohmeyer G, Ebert R, et al.

Hyperinsulinaemia in non-cirrhotic haemochromatosis: impaired hepatic insulin degradation? Diabetologia. 1984;26(6):441-4.

56. Dehghan A, Van Hoek M, Sijbrands EJ, Hofman A, Witteman JC. High serum uric acid as a novel risk factor for type 2 diabetes. Diabetes care. 2008;31(2):361-2.

57. Butler R, Morris AD, Belch JJ, Hill A, Struthers AD. Allopurinol normalizes endothelial dysfunction in type 2 diabetics with mild hypertension. Hypertension. 2000;35(3):746-51.

58. Nakagawa T, Hu H, Zharikov S, Tuttle KR, Short RA, Glushakova O, et al. A causal role for uric acid in fructose-induced metabolic syndrome. American journal of physiology Renal physiology. 2006;290(3):F625-31.

59. Lundman P, Boquist S, Samnegard A, Bennermo M, Held C, Ericsson CG, et al. A high-fat meal is accompanied by increased plasma interleukin- 6 concentrations. Nutrition, metabolism, and cardiovascular diseases : NMCD. 2007;17(3):195-202.

60. Johnson L, Mander AP, Jones LR, Emmett PM, Jebb SA. Energy-dense, low-fiber, high-fat dietary pattern is associated with increased fatness in childhood. The American journal of clinical nutrition. 2008;87(4):846-54.

61. Kien CL, Bunn JY, Ugrasbul F. Increasing dietary palmitic acid decreases fat oxidation and daily energy expenditure. The American journal of clinical nutrition. 2005;82(2):320-6. 
62. Mozaffarian D, Hao T, Rimm EB, Willett WC, Hu FB. Changes in diet and lifestyle and longterm weight gain in women and men. The New England journal of medicine. 2011;2011(364):2392404.

63. Vergnaud A-C, Norat T, Romaguera D, Mouw T, May AM, Travier N, et al. Meat consumption and prospective weight change in participants of the EPIC-PANACEA study. The American journal of clinical nutrition. 2010;92(2):398-407.

64. Hotamisligil GS. Inflammation, metaflammation and immunometabolic disorders. Nature. 2017;542(7640):177-85.

65. Farvid MS, Cho E, Chen WY, Eliassen AH, Willett WC. Adolescent meat intake and breast cancer risk. International journal of cancer. 2015;136(8):1909-20.

66. Binková B, Šmerhovský Z, Strejc P, Boubelík O, Stávková Z, Chvátalová I, et al. DNA-adducts and atherosclerosis: a study of accidental and sudden death males in the Czech Republic. Mutation Research/Fundamental and Molecular Mechanisms of Mutagenesis. 2002;501(1):115-28.

67. Lakshmi VM, Schut HA, Zenser TV. 2-Nitrosoamino-3-methylimidazo [4, 5-f] quinoline activated by the inflammatory response forms nucleotide adducts. Food and chemical toxicology. 2005;43(11):1607-17.

68. Bogen KT, Keating GA. US dietary exposures to heterocyclic amines 1. Journal of Exposure Science and Environmental Epidemiology. 2001;11(3):155.

69. Keating G, Bogen K. Estimates of heterocyclic amine intake in the US population. Journal of Chromatography B. 2004;802(1):127-33.

70. Kouvari M, Tyrovolas S, Panagiotakos DB. Red meat consumption and healthy ageing: A review. Maturitas. 2016;84:17-24.

71. Rothman KJ. BMI-related errors in the measurement of obesity. International journal of obesity (2005). 2008;32 Suppl 3:S56-9.

\section{Supplementary Figure legend:}

Supplementary FIGURE 1. Mediation model for the association between red meat consumption and Insulin/Glucose Haemostasis and inflammation; with body mass index (BMI), waist circumference (WC) and anthropometrically-predicted visceral adipose tissue (apVAT), visceral adipose tissue (VAl) and Lipid accumulation product (LAP) as mediators. Path $\alpha$ represents the regression coefficient for the association of red meat consumption with BMI, WC, apVAT, VAI and LAP "action theory". Path $\beta$ represents the regression coefficient for the association of BMI, WC, apVAT, VAI and LAP with Insulin/Glucose Haemostasis and inflammation "conceptual theory". The product of regression coefficients $\alpha$ and $\beta$ represents the mediated effect (indirect effect) of BMI, WC, apVAT, VAI and LAP ( $\alpha \# \beta)$. Path $\gamma^{\prime}$ represents the direct effect of red meat consumption with Insulin/Glucose Haemostasis and inflammation, after adjustment for BMI, WC, apVAT, VAI and LAP "direct effect". Path $y$ represents the simple total effect of red meat consumption on Insulin/Glucose Haemostasis and inflammation, without adjustment for BMI, WC, apVAT, VAI and LAP "total effect". 
Table 1. Age-, sex-, and race-adjusted mean of markers of insulin resistance and inflammation across quartiles of red meat consumption

\begin{tabular}{|c|c|c|c|c|c|}
\hline \multirow[t]{2}{*}{ Variables } & \multicolumn{4}{|c|}{ Quartiles of red meat consumption } & \multirow{5}{*}{$\begin{array}{l}\mathbf{p} \\
\text { value }^{\mathrm{a}}\end{array}$} \\
\hline & 1 & 2 & 3 & 4 & \\
\hline $\mathrm{N}$, & 4153 & 4158 & 4166 & 4144 & \\
\hline Median (25th-75th percentiles) & $5.5(2.2-$ & $11.1(9.8-$ & $32.4(27.6-$ & $58.4(46.3-$ & \\
\hline Meat Consumption (g/day) & 7.8) & 19.7) & 41.9) & 66.9) & \\
\hline Serum Hs-CRP (mg/dl) & $0.29 \pm 0.01$ & $0.36 \pm 0.01$ & $0.39 \pm 0.03$ & $0.48 \pm 0.01$ & $<0.001$ \\
\hline $\begin{array}{l}\text { Serum Apolipoprotein (B) } \\
\text { (mg/dL) }\end{array}$ & $91.3 \pm 0.86$ & $93.9 \pm 0.82$ & $96.4 \pm 0.98$ & $97.1 \pm 1.04$ & $<0.001$ \\
\hline Fasting blood glucose (mg/dl) & $97.4 \pm 0.65$ & $97.6 \pm 0.82$ & $100.2 \pm 0.49$ & $102.3 \pm 0.76$ & $<0.001$ \\
\hline Plasma Insulin $(\mu \mathrm{U} / \mathrm{mL})$ & $1.86 \pm 0.01$ & $1.93 \pm 0.02$ & $2.06 \pm 0.01$ & $2.19 \pm 0.01$ & $<0.001$ \\
\hline HOMA-IR & $0.69 \pm 0.03$ & $0.89 \pm 0.01$ & $1.06 \pm 0.01$ & $1.18 \pm 0.01$ & $<0.001$ \\
\hline HOMA-B & $4.29 \pm 0.01$ & $4.41 \pm 0.01$ & $4.62 \pm 0.02$ & $4.79 \pm 0.01$ & $<0.001$ \\
\hline HbA1c (\%) & $5.44 \pm 0.02$ & $5.49 \pm 0.01$ & $5.34 \pm 0.01$ & $5.28 \pm 0.02$ & 0.28 \\
\hline TyG index & $8.46 \pm 0.01$ & $8.59 \pm 0.01$ & $8.71 \pm 0.03$ & $8.89 \pm 0.01$ & $<0.001$ \\
\hline
\end{tabular}

HOMA-IR, Homeostatic model assessment of insulin resistance; HOMA-B, Homeostatic model assessment of B-cell function; TyG index, triglyceride-glucose index; $h S C R P$; high sensitivity C-reactive protein; HbA1c haemoglobin A1c. Values expressed as estimated mean and standard error.

${ }^{a} p$-values for linear trend across quartiles of hs-CRP. Variables were compared across quartiles of red meat consumption using analysis of covariance (ANCOVA) test. 
Table 2. Estimates of regression coefficients ( $95 \% \mathrm{Cls}$ ) for the association between red meat consumption (g/day), BMI, WC, apVAT, VAI and LAP (action theory), and markers of insulin resistance and inflammation (total effect) among US adults in NHANES

\begin{tabular}{|c|c|c|c|}
\hline Mediator & Estimate & $95 \% \mathrm{Cl}$ & $\mathbf{P}$ \\
\hline BMI & 0.34 & $(0.21-0.48)$ & $<0.001$ \\
\hline WC & 0.91 & (0.59-1.24) & $<0.001$ \\
\hline apVAT & 3.27 & $(0.95-5.42)$ & $<0.001$ \\
\hline LAP & 0.06 & $(0.04-0.08)$ & $<0.001$ \\
\hline VAI & 0.05 & $(0.03-0.07)$ & $<0.001$ \\
\hline \multicolumn{4}{|l|}{ Outcome } \\
\hline Serum Hs-CRP (mg/dl) & 0.03 & $(0.02-0.07)$ & 0.01 \\
\hline $\begin{array}{l}\text { Serum Apolipoprotein (B) } \\
(\mathrm{mg} / \mathrm{dL})\end{array}$ & 0.96 & $(0.45-1.12)$ & 0.01 \\
\hline $\begin{array}{l}\text { Fasting blood glucose } \\
\text { (mg/dl) }\end{array}$ & 0.69 & $(0.33-1.01)$ & 0.04 \\
\hline Plasma Insulin (uU/mL) & 0.03 & $(0.02-0.06)$ & $<0.001$ \\
\hline HOMA_IR & 0.04 & $(0.02-0.07)$ & $<0.001$ \\
\hline HOMA_B & 0.01 & $(-0.005-0.04)$ & 0.14 \\
\hline HbA1c (\%) & 0.01 & $(-0.003-0.04)$ & 0.12 \\
\hline TyG index & 0.04 & $(0.03-0.06)$ & $<0.001$ \\
\hline
\end{tabular}

Abbreviations: BMI: body mass index, WC, waist circumference, apVAT, Anthropometricallypredicted visceral adipose tissue , HOMA_IR, Homeostatic model assessment of insulin resistance ; HOMA_B, Homeostatic model assessment of B-cell function HOMA_S; Homeostatic model assessment of insulin sensitivity, TyG index, triglyceride-glucose index Hs-CRP; high senility C-reactive protein, HbA1c Glycated haemoglobin. All estimates were adjusted for age, sex, race/ethnicity, education, smoking and level of physical activity. Estimates for mediator and outcomes correspond to the regression coefficients $\alpha$ and $f$, respectively, in Figure 1 . 
Table 3. Estimates of regression coefficients ( $95 \% \mathrm{Cls}$ ) for the association between BMI, WC, apVAT, VAI and LAP with markers of insulin resistance and inflammation (conceptual theory) among US adults

\begin{tabular}{|c|c|c|c|c|c|c|c|c|c|c|c|c|c|c|c|}
\hline \multirow{2}{*}{$\begin{array}{l}\text { Outcom } \\
\text { es }\end{array}$} & \multicolumn{3}{|c|}{ BMI } & \multicolumn{3}{|c|}{ WC } & \multicolumn{3}{|c|}{ apVAT } & \multicolumn{3}{|c|}{ VAl } & \multicolumn{3}{|c|}{ LAP } \\
\hline & $\begin{array}{l}\text { Est } \\
\text { im } \\
\text { at } \\
\text { e }\end{array}$ & $\begin{array}{l}95 \% \\
\mathrm{Cl}\end{array}$ & $\mathbf{P}$ & $\begin{array}{l}\text { Es } \\
\text { ti } \\
\mathrm{m} \\
\text { at } \\
\text { e }\end{array}$ & $\begin{array}{l}95 \% \\
\mathrm{Cl}\end{array}$ & $\mathbf{P}$ & $\begin{array}{l}\text { Est } \\
\text { im } \\
\text { ate }\end{array}$ & $\begin{array}{l}95 \% \\
\mathrm{Cl}\end{array}$ & $\mathbf{P}$ & $\begin{array}{l}\text { Est } \\
\text { im } \\
\text { ate }\end{array}$ & $\begin{array}{l}95 \% \\
\mathrm{Cl}\end{array}$ & $\mathbf{P}$ & $\begin{array}{l}\text { Est } \\
\text { im } \\
\text { at } \\
\text { e }\end{array}$ & $\begin{array}{l}95 \% \\
\mathrm{Cl}\end{array}$ & $\mathbf{P}$ \\
\hline $\begin{array}{l}\text { Serum } \\
\text { Hs-CRP } \\
\text { (mg/dl) }\end{array}$ & $\begin{array}{l}0.0 \\
8\end{array}$ & $\begin{array}{l}0.08 \\
0- \\
0.08 \\
5\end{array}$ & $\begin{array}{l}<0 . \\
00 \\
1\end{array}$ & $\begin{array}{l}0 . \\
03\end{array}$ & $\begin{array}{l}0.03 \\
6- \\
0.03 \\
8\end{array}$ & $\begin{array}{l}<0 . \\
00 \\
1\end{array}$ & $\begin{array}{l}0.0 \\
09\end{array}$ & $\begin{array}{l}0.00 \\
89- \\
0.00 \\
96\end{array}$ & $\begin{array}{l}<0 . \\
00 \\
1\end{array}$ & $\begin{array}{l}0.4 \\
0\end{array}$ & $\begin{array}{l}0.38 \\
- \\
0.42\end{array}$ & $\begin{array}{l}<0 . \\
00 \\
1\end{array}$ & $\begin{array}{l}0 . \\
56\end{array}$ & $\begin{array}{l}0.52 \\
- \\
0.56\end{array}$ & $\begin{array}{l}<0 . \\
00 \\
1\end{array}$ \\
\hline $\begin{array}{l}\text { Serum } \\
\text { Apolipo } \\
\text { protein } \\
\text { (B) } \\
\text { (mg/dL) }\end{array}$ & $\begin{array}{l}0.5 \\
4\end{array}$ & $\begin{array}{l}0.46 \\
0- \\
0.63 \\
0\end{array}$ & $\begin{array}{l}<0 . \\
00 \\
1\end{array}$ & $\begin{array}{l}0 . \\
29\end{array}$ & $\begin{array}{l}0.26 \\
0- \\
0.33 \\
0\end{array}$ & $\begin{array}{l}<0 . \\
00 \\
1\end{array}$ & $\begin{array}{l}0.0 \\
9\end{array}$ & $\begin{array}{l}0.07 \\
3- \\
0.10 \\
2\end{array}$ & $\begin{array}{l}<0 . \\
00 \\
1\end{array}$ & $\begin{array}{l}14 . \\
23\end{array}$ & $\begin{array}{l}13.9 \\
5- \\
15.2 \\
6\end{array}$ & $\begin{array}{l}<0 . \\
00 \\
1\end{array}$ & $\begin{array}{l}13 \\
.6 \\
2\end{array}$ & $\begin{array}{l}12.5 \\
2- \\
14.6 \\
3\end{array}$ & $\begin{array}{l}<0 . \\
00 \\
1\end{array}$ \\
\hline $\begin{array}{l}\text { Fasting } \\
\text { blood } \\
\text { glucose } \\
\text { (mg/dl) }\end{array}$ & $\begin{array}{l}0.7 \\
7\end{array}$ & $\begin{array}{l}0.69 \\
0- \\
0.88 \\
0\end{array}$ & $\begin{array}{l}<0 . \\
00 \\
1\end{array}$ & $\begin{array}{l}0 . \\
36\end{array}$ & $\begin{array}{l}0.32 \\
0- \\
0.40 \\
0\end{array}$ & $\begin{array}{l}<0 . \\
00 \\
1\end{array}$ & $\begin{array}{l}0.0 \\
7\end{array}$ & $\begin{array}{l}0.06 \\
4- \\
0.09 \\
5\end{array}$ & $\begin{array}{l}<0 . \\
00 \\
1\end{array}$ & $\begin{array}{l}8.2 \\
5\end{array}$ & $\begin{array}{l}7.62 \\
- \\
9.12\end{array}$ & $\begin{array}{l}<0 . \\
00 \\
1\end{array}$ & $\begin{array}{l}7 . \\
42\end{array}$ & $\begin{array}{l}6.39 \\
- \\
8.54\end{array}$ & $\begin{array}{l}<0 . \\
00 \\
1\end{array}$ \\
\hline $\begin{array}{l}\text { Plasma } \\
\text { Insulin(u } \\
\mathrm{U} / \mathrm{mL} \text { ) }\end{array}$ & $\begin{array}{l}0.0 \\
5\end{array}$ & $\begin{array}{l}0.05 \\
4- \\
0.05 \\
9\end{array}$ & $\begin{array}{l}<0 . \\
00 \\
1\end{array}$ & $\begin{array}{l}0 . \\
02\end{array}$ & $\begin{array}{l}0.02 \\
4- \\
0.02 \\
6\end{array}$ & $\begin{array}{l}<0 . \\
00 \\
1\end{array}$ & $\begin{array}{l}0.0 \\
06\end{array}$ & $\begin{array}{l}0.00 \\
5- \\
0.00 \\
7\end{array}$ & $\begin{array}{l}<0 . \\
00 \\
1\end{array}$ & $\begin{array}{l}0.4 \\
0\end{array}$ & $\begin{array}{l}0.38 \\
- \\
0.42\end{array}$ & $\begin{array}{l}<0 . \\
00 \\
1\end{array}$ & $\begin{array}{l}0 . \\
44\end{array}$ & $\begin{array}{l}0.43 \\
- \\
0.46\end{array}$ & $\begin{array}{l}<0 . \\
00 \\
1\end{array}$ \\
\hline $\begin{array}{l}\text { HOMA_I } \\
\text { R }\end{array}$ & $\begin{array}{l}0.0 \\
6\end{array}$ & $\begin{array}{l}0.06 \\
1- \\
0.06 \\
5\end{array}$ & $\begin{array}{l}<0 . \\
00 \\
1\end{array}$ & $\begin{array}{l}0 . \\
02\end{array}$ & $\begin{array}{l}0.02 \\
8- \\
0.03 \\
0\end{array}$ & $\begin{array}{l}<0 . \\
00 \\
1\end{array}$ & $\begin{array}{l}0.0 \\
07\end{array}$ & $\begin{array}{l}0.00 \\
6- \\
0.00 \\
8\end{array}$ & $\begin{array}{l}<0 . \\
00 \\
1\end{array}$ & $\begin{array}{l}0.4 \\
7\end{array}$ & $\begin{array}{l}0.44 \\
- \\
0.49\end{array}$ & $\begin{array}{l}<0 . \\
00 \\
1\end{array}$ & $\begin{array}{l}0 . \\
51\end{array}$ & $\begin{array}{l}0.49 \\
- \\
0.52\end{array}$ & $\begin{array}{l}<0 . \\
00 \\
1\end{array}$ \\
\hline $\begin{array}{l}\text { HOMA_ } \\
\text { B }\end{array}$ & $\begin{array}{l}0.0 \\
3\end{array}$ & $\begin{array}{l}0.03 \\
4- \\
0.03 \\
9\end{array}$ & $\begin{array}{l}<0 . \\
00 \\
1\end{array}$ & $\begin{array}{l}0 . \\
01\end{array}$ & $\begin{array}{l}0.01 \\
6- \\
0.01 \\
8\end{array}$ & $\begin{array}{l}<0 . \\
00 \\
1\end{array}$ & $\begin{array}{l}0.0 \\
04\end{array}$ & $\begin{array}{l}0.00 \\
3- \\
0.00 \\
5\end{array}$ & $\begin{array}{l}<0 \\
00 \\
1\end{array}$ & $\begin{array}{l}0.2 \\
3\end{array}$ & $\begin{array}{l}0.21 \\
- \\
0.25\end{array}$ & $\begin{array}{l}<0 . \\
00 \\
1\end{array}$ & $\begin{array}{l}0 . \\
28\end{array}$ & $\begin{array}{l}0.26 \\
- \\
0.30\end{array}$ & $\begin{array}{l}<0 . \\
00 \\
1\end{array}$ \\
\hline $\begin{array}{l}\text { HbA1c } \\
\text { (\%) }\end{array}$ & $\begin{array}{l}0.0 \\
2\end{array}$ & $\begin{array}{l}0.02 \\
3- \\
0.02 \\
7\end{array}$ & $\begin{array}{l}<0 . \\
00 \\
1\end{array}$ & $\begin{array}{l}0 . \\
01\end{array}$ & $\begin{array}{l}0.01 \\
0- \\
0.01 \\
2\end{array}$ & $\begin{array}{l}<0 . \\
00 \\
1\end{array}$ & $\begin{array}{l}0.0 \\
02\end{array}$ & $\begin{array}{l}0.00 \\
1- \\
0.00 \\
3\end{array}$ & $\begin{array}{l}<0 . \\
00 \\
1\end{array}$ & $\begin{array}{l}0.2 \\
1\end{array}$ & $\begin{array}{l}0.19 \\
- \\
0.23\end{array}$ & $\begin{array}{l}<0 . \\
00 \\
1\end{array}$ & $\begin{array}{l}0 . \\
20\end{array}$ & $\begin{array}{l}0.19 \\
- \\
0.22\end{array}$ & $\begin{array}{l}<0 . \\
00 \\
1\end{array}$ \\
\hline $\begin{array}{l}\text { TyG } \\
\text { index }\end{array}$ & $\begin{array}{l}0.0 \\
2\end{array}$ & $\begin{array}{l}0.02 \\
7- \\
0.03 \\
1\end{array}$ & $\begin{array}{l}<0 . \\
00 \\
1\end{array}$ & $\begin{array}{l}0 . \\
01\end{array}$ & $\begin{array}{l}0.01 \\
3- \\
0.01 \\
5\end{array}$ & $\begin{array}{l}<0 . \\
00 \\
1\end{array}$ & $\begin{array}{l}0.0 \\
04\end{array}$ & $\begin{array}{l}0.00 \\
3- \\
0.00 \\
5\end{array}$ & $\begin{array}{l}<0 . \\
00 \\
1\end{array}$ & $\begin{array}{l}0.7 \\
7\end{array}$ & $\begin{array}{l}0.72 \\
- \\
0.80\end{array}$ & $\begin{array}{l}<0 . \\
00 \\
1\end{array}$ & $\begin{array}{l}0 . \\
64\end{array}$ & $\begin{array}{l}0.63 \\
- \\
0.66\end{array}$ & $\begin{array}{l}<0 . \\
00 \\
1\end{array}$ \\
\hline
\end{tabular}

Abbreviations: BMI: body mass index, WC, waist circumference, apVAT, Anthropometricallypredicted visceral adipose tissue ,HOMA_IR, Homeostatic model assessment of insulin resistance; HOMA_B, Homeostatic model assessment of B-cell function HOMA_S; Homeostatic model assessment of insulin sensitivity, TyG index, triglyceride-glucose index, Hs-CRP; high senility Creactive protein. All estimates were adjusted for age, sex, race/ethnicity, educational, smoking and level of physical activity. Regression coefficient $\beta$ is shown in Figure 1. 
Table 4. Direct and indirect effects of red meat consumption on markers of insulin resistance and inflammation with BMI, WC, apVAT, VAI and LAP as mediators among US adults

\begin{tabular}{|c|c|c|c|c|c|}
\hline \multirow{2}{*}{$\begin{array}{l}\text { Mediator and } \\
\text { outcomes }\end{array}$} & \multicolumn{2}{|c|}{ Direct effect $\left(f^{\prime}\right)$} & \multicolumn{2}{|c|}{ Indirect effect $(\alpha \# \beta) 3$} & \multirow{3}{*}{$\begin{array}{l}\text { Proportion } \\
\text { of } \\
\text { mediation } \\
\%\end{array}$} \\
\hline & \multirow{2}{*}{$\begin{array}{l}\text { Estima } \\
\text { te }\end{array}$} & \multirow[t]{2}{*}{$\mathbf{P}$} & \multirow[t]{2}{*}{ Estimate } & \multirow{2}{*}{$\begin{array}{l}\text { Sobel test } \\
\text { statistic }\end{array}$} & \\
\hline BMI & & & & & \\
\hline $\begin{array}{l}\text { Serum Hs-CRP } \\
\text { (mg/dl) }\end{array}$ & 0.004 & 0.692 & 0.029 & $<0.001$ & $82.1 \%$ \\
\hline $\begin{array}{l}\text { Serum } \\
\text { Apolipoprotein } \\
\text { (B) }(\mathrm{mg} / \mathrm{dL})\end{array}$ & 0.888 & 0.023 & 0.201 & $<0.001$ & $21.1 \%$ \\
\hline $\begin{array}{l}\text { Fasting blood } \\
\text { glucose (mg/dl) }\end{array}$ & 0.382 & 0.312 & 0.312 & $<0.001$ & $27.2 \%$ \\
\hline $\begin{array}{l}\text { Plasma Insulin } \\
(\mathrm{uU} / \mathrm{mL})\end{array}$ & 0.016 & 0.079 & 0.022 & $<0.001$ & $66.9 \%$ \\
\hline HOMA_IR & 0.020 & 0.032 & 0.025 & $<0.001$ & $58.1 \%$ \\
\hline HOMA_B & 0.002 & 0.795 & 0.013 & $<0.001$ & $12.3 \%$ \\
\hline HbA1c (\%) & 0.055 & 0.623 & 0.009 & $<0.001$ & $26.1 \%$ \\
\hline TyG index & 0.039 & $<0.001$ & 0.010 & $<0.001$ & $5.3 \%$ \\
\hline \multicolumn{6}{|l|}{ WC } \\
\hline $\begin{array}{l}\text { Serum Hs-CRP } \\
(\mathrm{mg} / \mathrm{dl})\end{array}$ & 0.008 & 0.865 & 0.034 & $<0.001$ & $69.1 \%$ \\
\hline $\begin{array}{l}\text { Serum } \\
\text { Apolipoprotein } \\
\text { (B) }(\mathrm{mg} / \mathrm{dL})\end{array}$ & 0.695 & 0.046 & 0.266 & $<0.001$ & $22.3 \%$ \\
\hline $\begin{array}{l}\text { Fasting blood } \\
\text { glucose (mg/dl) }\end{array}$ & 0.203 & 0.562 & 0.371 & $<0.001$ & $23.1 \%$ \\
\hline $\begin{array}{l}\text { Plasma Insulin } \\
(\mathrm{uU} / \mathrm{mL})\end{array}$ & 0.014 & 0.112 & 0.024 & $<0.001$ & $52.1 \%$ \\
\hline HOMA_IR & 0.019 & 0.043 & 0.028 & $<0.001$ & $46.5 \%$ \\
\hline HOMA_B & 0.001 & 0.956 & 0.015 & $<0.001$ & $4.23 \%$ \\
\hline HbA1c (\%) & 0.001 & 0.846 & 0.011 & $<0.001$ & $20.4 \%$ \\
\hline TyG index & 0.033 & $<0.001$ & 0.013 & $<0.001$ & $34.5 \%$ \\
\hline \multicolumn{6}{|l|}{ apVAT } \\
\hline $\begin{array}{l}\text { Serum Hs-CRP } \\
(\mathrm{mg} / \mathrm{dl})\end{array}$ & -0.023 & 0.336 & 0.030 & $<0.001$ & $95.1 \%$ \\
\hline $\begin{array}{l}\text { Serum } \\
\text { Apolipoprotein } \\
\text { (B) }(\mathrm{mg} / \mathrm{dL})\end{array}$ & -0.022 & 0.762 & 0.212 & 0.166 & $72.1 \%$ \\
\hline $\begin{array}{l}\text { Fasting blood } \\
\text { glucose }(\mathrm{mg} / \mathrm{dl})\end{array}$ & 0.112 & 0.623 & 0.293 & $<0.001$ & $16.3 \%$ \\
\hline $\begin{array}{l}\text { Plasma Insulin } \\
(\mathrm{uU} / \mathrm{mL})\end{array}$ & 0.031 & 0.042 & 0.016 & 0.166 & $40.6 \%$ \\
\hline HOMA_IR & 0.030 & 0.109 & 0.019 & 0.143 & $36.1 \%$ \\
\hline HOMA_B & 0.022 & 0.245 & 0.011 & 0.145 & $33.1 \%$ \\
\hline HbA1c (\%) & 0.003 & 0.831 & 0.009 & $<0.001$ & $13.1 \%$ \\
\hline TyG index & 0.020 & 0.032 & 0.013 & $<0.001$ & $20.1 \%$ \\
\hline
\end{tabular}




\begin{tabular}{|c|c|c|c|c|c|}
\hline \multicolumn{6}{|l|}{ VAI } \\
\hline $\begin{array}{l}\text { Serum Hs-CRP } \\
(\mathrm{mg} / \mathrm{dl})\end{array}$ & 0.016 & 0.205 & 0.021 & $<0.001$ & $6.2 \%$ \\
\hline $\begin{array}{l}\text { Serum } \\
\text { Apolipoprotein } \\
\text { (B) }(\mathrm{mg} / \mathrm{dL})\end{array}$ & 0.215 & 0.563 & 0.682 & $<0.001$ & $43.1 \%$ \\
\hline $\begin{array}{l}\text { Fasting blood } \\
\text { glucose (mg/dl) }\end{array}$ & 0.105 & 0.777 & 0.452 & $<0.001$ & $4.1 \%$ \\
\hline $\begin{array}{l}\text { Plasma Insulin } \\
(\mathrm{uU} / \mathrm{mL})\end{array}$ & 0.021 & 0.039 & 0.018 & $<0.001$ & $3.7 \%$ \\
\hline HOMA_IR & 0.021 & 0.019 & 0.022 & $<0.001$ & $3.4 \%$ \\
\hline HOMA_B & 0.007 & 0.653 & 0.011 & $<0.001$ & $6.2 \%$ \\
\hline HbA1c (\%) & 0.001 & 0.635 & 0.11 & $<0.001$ & $2.9 \%$ \\
\hline TyG index & 0.005 & 0.038 & 0.042 & $<0.001$ & $19.7 \%$ \\
\hline \multicolumn{6}{|l|}{ LAP } \\
\hline $\begin{array}{l}\text { Serum Hs-CRP } \\
\text { (mg/dl) }\end{array}$ & 0.003 & 0.865 & 0.036 & $<0.001$ & $16.2 \%$ \\
\hline $\begin{array}{l}\text { Serum } \\
\text { Apolipoprotein } \\
\text { (B) }(\mathrm{mg} / \mathrm{dL})\end{array}$ & 0.101 & 0.723 & 0.808 & $<0.001$ & $16.2 \%$ \\
\hline $\begin{array}{l}\text { Fasting blood } \\
\text { glucose (mg/dl) }\end{array}$ & 0.033 & 0.986 & 0.542 & $<0.001$ & $8.2 \%$ \\
\hline $\begin{array}{l}\text { Plasma Insulin } \\
(\mathrm{uU} / \mathrm{mL})\end{array}$ & 0.011 & 0.214 & 0.027 & $<0.001$ & $18.6 \%$ \\
\hline HOMA_IR & 0.016 & 0.123 & 0.031 & $<0.001$ & $14.8 \%$ \\
\hline HOMA_B & 0.001 & 0.865 & 0.017 & $<0.001$ & $31.2 \%$ \\
\hline HbA1c (\%) & -0.011 & 0.911 & 0.014 & $<0.001$ & $6.3 \%$ \\
\hline TyG index & 0.004 & 0.320 & 0.043 & $<0.001$ & $6.32 \%$ \\
\hline
\end{tabular}

Abbreviations: BMI: body mass index, WC, waist circumference, apVAT, Anthropometricallypredicted visceral adipose tissue , HOMA_IR, Homeostatic model assessment of insulin resistance ; HOMA_B, Homeostatic model assessment of B-cell function HOMA_S; Homeostatic model assessment of insulin sensitivity, TyG index, triglyceride-glucose index Hs-CRP; high senility C-reactive protein. All estimates were adjusted for age, sex, race/ethnicity, educational, smoking and level of physical activity. Regression coefficients $\alpha, 6$, and $f^{\prime}$ are shown in Figure 1. 